\title{
AVT as Intercultural Mediation
}

Marie-Noëlle Guillot, University of East Anglia, and Maria Pavesi, Università Pavia m.guillot@uea.ac.uk; mariagabriella.pavesi@unipv.it

\begin{abstract}
This article addresses a question central for this special issue of Multilingua on audiovisual translation (AVT), of the relationship between the cross-cultural and the intercultural in audiovisual translation. The question underpins fundamental debates in the emergent field of AVT as cross/intercultural mediation, the focus in this volume, with subtitling and dubbing the two main interlingual modes considered in its pages from an interdisciplinary perspective embracing translation and audiovisual translation studies, pragmatics and cross-cultural pragmatics and film studies. The article doubles up as the introduction for the special issue, and provides its rationale and contents.
\end{abstract}

Keywords: audiovisual translation, subtitling, dubbing, cross/intercultural mediation. 


\section{Audiovisual translation as intercultural mediation - what's the story?}

This special issue on Audiovisual Translation (AVT) as intercultural mediation is a response to a pressing need to coordinate and develop research in the emergent field of Audiovisual Translation (AVT) as intercultural mediation, and address topical but still under-explored issues of linguistic and cultural representation in telecinematic text.

While the dissemination of cultural products on a global scale has reached unprecedented levels, our understanding of what is at stake in processes of interlingual mediation through AVT has lagged behind, and we have limited understanding of what linguistic and cultural representations they convey to the public, and of their societal impact. Several questions can be asked: what picture is given by foreign-language films via subtitling or dubbing of how people talk and negotiate interpersonal meaning and interaction in other languages? What representations are thus conveyed via AVT of the languages mediated from, across the range of their varieties, contexts of use and registers, in foreign films or other cultural media products? How do foreign-language film audiences understand foreign films and respond to the linguistic and cultural representations conveyed through subtitling or dubbing and audiovisual translation? What is the potential of translated foreign films to promote intercultural literacy?

The special issue capitalizes on recent work on AVT from a cross-cultural pragmatics perspective to put these questions more firmly onto the research agenda, and give impetus, greater visibility and research reliability to work in this new domain. While aiming to capture the synergies of emergent research in the pragmatics of fiction and fictive speech, the volume more generally intends to give the field of AVT as cross- and intercultural mediation dependability and methodological robustness. Conversely, it proposes to offer pragmatics, sociopragmatics/linguistics and other key disciplines like film studies the benefit of a novel perspective and understanding of telecinematic text across languages.

The contributions to this special issue arise from the activities of the AHRC Research Network project Tapping the Power of Foreign Language Films: Audiovisual Translation as Cross-cultural Mediation (TPFF). The project was set up to push the frontiers of research in this domain, while the present issue is designed to give momentum to the surge of interdisciplinary interest for AVT as intercultural mediation that the project has generated ${ }^{1}$.

\footnotetext{
1 Project AH/N007026/1 Principal Investigator Guillot, Co-Investigator Desilla, core team members Mingant, Pavesi, Zabalbeascoa; www.filmsintranslation.org. The TPFF team would like to thank the UK Arts and Humanities Research Council for supporting and funding the project, and the University of East Anglia in Norwich and University College London for hosting the project's research events.
} 
The next section provides a contextualisation of AVT in this perspective, as a preamble for considering the types and levels of engagement involved in dealing with intercultural mediation in AVT and accounting for the architecture of their interdependence (Section 3). The volume is in three parts: AVT as intercultural mediation and its underpinnings, AVT as a tool for crosscultural mediation and intercultural literacy, AVT and its publics, with seven articles covering both subtitling and dubbing and dealing with seven languages, in various guises (English, French, German, Greek, Japanese, Italian and Spanish). They are outlined in the contents section.

The special issue's drive to promote methodological robustness and accountability in the study of AVT as intercultural mediation is epitomised in the methodological outline that comes with each of the contributions. The outlines are brief but comprehensive summaries designed to facilitate comparison and promote falsifiability, and to this end use the same framework with the following key headings: focus, underpinning theory, research question and/or underlying assumptions, languages, type of study (e.g. case study, corpus study), methodology, data, experimental procedure or research instruments, (main) results and conclusions, acknowledged limitations, implications/uses.

\section{Audiovisual Translation as Intercultural Mediation in context: the picture so far}

Audiovisual translation research began to emerge in the late 1990's and is a relatively new discipline. Between the first special issue on the topic (Gambier 2003) and his reprise by Ramos Pinto and Gambier in 2016 with a special issue on AVT and its theoretical and methodological challenges, there has been a gradual build up, of work chiefly devoted to typologizing language issues and aspects of cultural transfer in interlingual subtitling and dubbing, and strategies for dealing with them in view of the practical and technical constraints that inevitably affect choices (display space and time and shift from speech to writing for subtitling, synchrony for both modes, lip synchrony in particular for dubbing, inter alia) (Chaume 2012, Díaz Cintas and Remael 2007). Until recently, however, pragmatics had been represented largely indirectly, and unevenly.

For AVT and cross-cultural representation, i.e. linguistic and cultural representation approached contrastively, but ultimately as a vehicle for intercultural literacy for audiences, there have been two types of research:

- specialised research drawing on accredited methodologies to analyse communicative practices cross-culturally, i.e. with an overtly identified pragmatics and sociopragmatic 
stance and methodological framework, on politeness, speech acts like greetings, compliments and advice, swearing and insults, interpersonal address, implicature, conversational moves, for example (Bruti 2009, Guillot 2010, Guillot 2016, Pinto 2010 for subtitling; Bonsignori et al 2011, Pavesi 2012 for dubbing), with a subset focusing on interpersonal dynamics through the vista of different features (politeness, sequential build up, the construal of naturalness, implicature; Hatim and Mason 1997, Remael 2003, Pérez-González 2007, Desilla 2012 respectively). (see Guillot 2017 for a full review). Studies of this kind are relatively recent, and still comparatively few.

- 'incidental' research, i.e. generated as a by-product of investigations on translation issues and strategies pertaining to recurrent concerns in AVT, such as culture specific reference, humour, depiction of language variation - geolects, sociolects, idiolects -, orality, etc., so with only an implicit interest in how language is used in social contexts and meaning negotiated in verbal exchange and in this sense pragmatically (e.g. Forchini 2013, Ranzato 2010 for AVT generally, Longo 2009 for subtitling, Matalama 2009, Romero Fresco 2009, Baños 2014, Pavesi 2016 for dubbing). There has been more research of this type but the overall picture is still limited, and fragmented.

Evidence has been building up of late of a more focused interest in language in AVT, and in the language of AVT, as a key component in multimodal cinematic discourse, and acknowledgement of the centrality of linguistic and cultural representation in AVT mediated films and other media in AVT research. This is manifest in a recent spate of publications in edited volumes (Pavesi et al 2014, Dìaz-Cintas and Neves 2015, Ranzato and Zanotti 2018) or journals (e.g. De Pablos fc. 2019). It is finding a voice in calls to recognise the distinctiveness and specificities of AVT mediated cinematic discourse as a medium of expression and appraise its implications from the point of view of reception (Guillot 2017, 2019 for subtitling, Pavesi 2018 for dubbing), with interest and interdisciplinary input from pragmatics also beginning to build up the picture (see Messerli 2017 for example, and this volume).

The fields now needs concerted effort to achieve critical mass. Pooling findings and methodologies is crucial to promote the comparability, reliability and complementarity of studies, and build up a catalogue of recurrent aspects and features, translation strategies and, critically, pragmatic specificity. The job of description is also a necessity for reception research into interpretation and responses to AVT-mediated cultural products from the perspective of cross-cultural understanding, so far largely uncatered for. A basic issue is access to dedicated 
research data in usable form, on the depiction of communicative practices governed in interlingual subtitling and dubbing by different cultural schemata and linguistic encoding, and by the constraints and specificities peculiar to the intersemiotic film medium.

In practice, subtitling and dubbing, the dialogues they represent and the cinematic context in which they are inextricably embedded produce distinctive processing conditions for audiences and an experience which, while rooted in the cross-cultural, is also intercultural, by dint of recipients' own linguistic, cultural and sociolinguistic make up. The challenge for AVT, and for AVT research, is to capture this unique interplay of the cross- and intercultural. This is a dual undertaking, which includes accounting for AVT both in its potential to mean as a distinctive and autonomous expressive code and in its potential to affect perception interculturally.

What is called for in the first instance is a more focused picture of the overall architecture of the levels and frames of references that AVT engages as cross and inter-cultural mediation, within the double layeredness of telecinematic communication.

\section{Cross- and intercultural mediation in AVT: an architecture of interdependence}

To deal with cross- and intercultural mediation in AVT, we need to foreground the doublelayeredness of telecinematic communication. This is fundamental for appreciating the mediation process in all its complexity. It involves different frames of reference and spans several levels in the overall architecture of the multimodal product. A first level brings in the original text in the source language and culture and overlaps with the diegetic layer of communication between characters: here the original story is narrated and characters converse on screen staging practices rooted in the source culture. Both intercultural and cross-cultural communication can occur at this level, either when non-native speakers interact with native speakers and other non-native speakers in the same fictional language, or each time diverse languages and dialects are represented on screen. Hence, in multilingual and multicultural films, cross-cultural mediation, implemented as intradiegetic interpretation, contextual translation or main language subtitling, is local, a fact of the original telecinematic text, and ultimately performed for the benefit of the source, receiving audience.

At the next level, the text gets into the stage of audiovisual translation. Level two centres on "the translator", i.e. the abstract, collective figure collapsing into one all agents involved in the audiovisual translation process. Communication between level one and level two is monodirectional; the translator activates his or her own interpretative frames and carries out cross-cultural comparisons in order to understand the source text as a culturally entrenched 
product and rearticulate it in a different language, and for a novel audience embedded in a target culture. As Liddicoat has it "[i]ntercultural mediators both analyse the meanings of the others constructed within cultural framings and provide those who do not share a cultural framing with the means to understand diverse others" (Liddicoat 2016: 355). Source and target languages and cultures alike are pivotal in the meaning making process. Cross-linguistic mediation at this stage can be both an intrapersonal activity, inside the individual translator, and an interpersonal process, being shared by a group of translation agents, who make sense of the source text and relay it as a target text to an anticipated target audience.

With level three, which corresponds to the extradiegetic layer, the focus shifts onto the foreign audience. Viewers watch scenes and actions that take place within the source culture but in the target language. They are involved simultaneously and monodirectionally in intercultural and cross-cultural communication, differentially depending on the translation mode, subtitling or dubbing. In dubbing, the dialogue is revoiced in the target language as characters are made to speak the foreign audience's language, and communication between characters and viewers is prototypically intercultural. However, viewers may also gain insights into the source language and culture thanks to the translator's cross-cultural mediation and activation of different frames of reference, interpretative frames and cultural asynchrony. Viewers' access to the source culture will vary depending on the degree of acculturation, foreignisation or hybridisation performed by the translator. In dubbing the visual component arguably highlights the foreign in the translated AV text and may identify a specific source culture, although with more or less salience for individual viewers. The unchangeability of the visual frame is critically prominent in this AVT mode as it makes complete acculturation impossible despite full text replacement, while bringing to the fore the inherently cross-cultural dimension of all translations of multimodal texts.

A different approach applies to subtitling, where the source dialogue is preserved in the target version, although variably available to viewers as a function of their competence in the source language, familiarity with the source culture, previous experience with subtitles, etc. Whereas with subtitling the potential is there overtly for fuller cross-cultural communication, in most cases viewers' experience will fall somewhere on a continuum, from considerable access to the meaning and articulation of the original message to no access except for the paralinguistic features of speech production and voice quality, with also varying degrees of mindful processing (see Katan 2014). In the case of totally unknown languages, subtitling is not dissimilar from dubbing, where communication is intercultural to a large extent and the cross-cultural understanding is mediated by the translator. That is, from level two to level three intercultural mediation brings about interlingual representations of representations (Guillot 2012: 482). 
Finally, in the intercultural encounters embedded in the AVT context, given elements from the two cultures in contact interact together and ad hoc traits materialise dynamically in the specific mediation context, as a result of both what is normed in AVT and what emerges on the specific mediating occasion (Kecskes 2014: 5).

\section{Contents}

In the first section of this special Multilingual issue, $A V T$ as intercultural mediation and its underpinnings, the debates identified earlier in this opening article are taken up in Guillot, Messerli and Ranzato's contextualising reconceptualisations of issues from different perspectives, with complementary pieces set to mark a turning point for AVT. Guillot sets the scene with a new type of cross-linguistic-study, of representational strategies in subtitling from English into Romance and Germanic languages, and a shift to theoretical concerns harnessed to an emergent AV text meaning- and viewer sense-making dialectic. Subtitling has expressive means and can avail itself of strategies that transcend linguistic difference, and are integral to the characterisation of this AVT mode as a medium of expression in its own right, in all its distinctiveness. With this key finding and those relating to differential interplays of modespecific and language specific representational strategies across the languages of the dataset, the study is a further challenge to deficit oversimplification. It recognizes in subtitling a capacity for sense-making central for the (re)conceptualisation of AVT modes as communication agents within the participation structure of reception, in line with calls from pragmatics. Messerli takes the argument a significant step further as the champion of these calls, with his discussion of (German to English) subtitles as communicative agents from a pragmatics of fiction angle, within a research paradigm that does not primarily view subtitles as translation products, but as 'an additional affordance for the communication with a culturally and linguistically Other target audience'. Subtitles' communicative effects are shown to be achieved as part of a jointcinematic meaning that engages all other affordances of film- making, and by a collective sender from three different loci: the diegetic world of the narrative fiction, the film's place of origin and the cultural space within which the audience is situated. In Ranzato, AVT issues are documented by reference to the archetypal and perennial challenges of social and regional dialect and idiolect representation, in film dialogues and in dubbing. While highlighting the limitations of dubbing in this respect, and neglect in particular of representationally key prosodic and phonetic features, Ranzato also celebrates dubbing's covert creative potential with a call for bolder strategies, of 
the kind deployed for comedic ends but overlooked elsewhere, as vehicles for the cross-cultural travel of sociolinguistic messages

The second part homes in on $A V T$ as a resource for intercultural literacy and crosscultural mediation, with two studies of communicative practices, both firmly grounded in cross-cultural pragmatics, investigated through the lens of different linguistic phenomena and their representation in dubbing (Pavesi and Formentelli, Ghia). Pavesi and Formentelli provide a comparative and contrastive study of insults that fits in spot on with the concerns of the volume by focussing on cross-cultural mediation as hybridisation, deriving from the close transfer of original communicative norms by means of typical target language models. In dubbing, the finegrained corpus analysis demonstrates, an array of frames of reference can be activated that allow receiving audiences a unique access to foreign communication practices from the perspective of their native language and culture. Likewise in line with the avenues we have been trying to promote in the present issue, Ghia deals with pragmatic questions, other key features of interaction on screen, uncovering their twofold facet as index of alignment and disalignment in audiovisual discourse and delving into the strategies used in their coding cross-linguistically. While the functions served by pragmatic questions (i.e. non-questioning, rhetorical interrogatives) in the English dialogues are carried through to dubbed Italian, the means differ across original and target versions in intriguing ways by reflecting the resources available in the two languages.

With the last section, $A V T$ and its publics, Desilla shifts our attention and questions to processes of reception, with a case study of audience response to misunderstandings in original and subtitled film dialogues that builds on her prior work on cross-cultural inferences from a relevance theory standpoint, with application to Greek, in one of very few studies still to go beyond psycholinguistic processes in the analysis of audience responses. Misunderstandings, of both the genuine and feigned types identified, are shown to operate across the two layers of filmic communication with important comedic and narrative functions. Active audience coparticipation is a key meaning-making ingredient, resulting in particular pragmatic challenges for subtitling and for subtitlers, with observed responses also raising significant questions about the nature of processes of comprehension. In the final piece of the volume Kirsch brings in a completely different angle with her postscript from film studies, a sound reminder of the range of factors involved in the production and dissemination of media and cultural products abroad, here with application to Japanese exports, and their impact on our sense and perceptions of crossculturality beyond what AVT analysts deal with. Her insights into the intricate network of people and processes that shape the choices made on behalf of audiences 'abroad' before they even get 
to go to the cinema are a telling demonstration that the journey of a film prior to its translation is indeed as complex and consequential as translation itself for cross- and intercultural mediation.

\section{References}

Baños, Rocío 2014. Orality markers in Spanish native and dubbed sitcoms: Pretended spontaneity and prefabricated orality', Meta 59(2). 406-435.

Bonsignori, Veronica, Bruti, Silvia \& Masi, Silvia 2011. Formulae across languages: English greetings, leave-takings and good wishes in dubbed Italian in Adriana Şerban, Anna Matamala, \& Jean-Marc Lavaur (eds.) Audiovisual Translation in Close-up: Practical and Theoretical Approaches, 23-44. Bern: Peter Lang.

Bruti, Silvia 2009. The translation of compliments in subtitles in Jorge Díaz Cintas (ed.) New Trends in Audiovisual Translation, 226-238. Clevedon: Multilingual Matters.

Chaume, Frederic 2012. Audiovisual Translation: Dubbing. London Routledge.

Desilla, Louisa 2012. Implicatures in film: construal and functions in Bridget Jones romantic comedies. Journal of Pragmatics 44 (1). 30-5.

De Pablos Carlos 2019. "I'm so sorry to disturb you but I wonder if I could have your autograph versus ¿Me firma un autógrafo por favour?” Contrastive (In)Directness in Subtitling in Rebecca Tipton \& Desilla Louisa Routledge Handbook Translation and Pragmatics, XXXX. London: Routledge

Díaz-Cintas, Jorge and Remael, Aline 2007. Audiovisual Translation: Subtitling. Manchester: St Jerome.

Díaz-Cintas, Jorge and Neves, Josélia (eds.) 2015. Audiovisual Translation: Tacking Stock. Newcastle upon Tyne: Cambridge Scholars Publishing.

Forchini, Pierfranca 2013. A diachronic study of familiarizers ('man', 'guys', 'buddy', 'dude') in movie language. Perspectives: Studies in Translatology 21 (4). 504-525.

Guillot, Marie-Noëlle 2010. Film subtitles from a cross-cultural pragmatics perspective: Issues of linguistic and cultural representation. The Translator 16 (1).: 67-92.

Guillot, Marie-Noëlle. 2012. Stylization and representation in subtitles: can less be more? Perspectives: Studies in Translatology 20(4). 479-494.

Guillot, Marie-Noëlle 2016a. Communicative rituals and audiovisual translation - representation of otherness in film subtitles. META 61 (3). 606-628. 
Guillot Marie-Noëlle 2017 Subtitling and dubbing in telecinematic text in Miriam A. Locher \& Andreas H. Jucker (eds.). Pragmatics of Fiction. 397-424. Berlin: Mouton De Gruyter.

Guillot Marie-Noëlle 2019 Subtitling on the cusp of its futures in Luis Pérez-González (ed.) The Routledge of Audiovisual Translation. London: Routledge.

Hatim, Basil \&Mason, Ian 1997. The Translator as Communicator. London: Routledge.

Katan, David 2014. Intercultural communication, mindful translation and squeezing "culture" onto the screen in Beatrice Garzelli \&Michela Baldo (eds) Subtitling and intercultural communication. European languages and beyond, 55-75. Pisa: ETS...

Liddicoat, Anthony J. 2016. Intercultural mediation,intercultural communication and translation. Perspectives: Studies in Translatology 24(3). 354-364.

Longo, Abele 2009. Subtitling the Italian South.", in New Trends in Audiovisual Translation in Jorge Díaz Cintas (ed.), 99-108. Clevedon: Multilingual Matters.

Matamala, Anna 2009. Interjections in original and dubbed sitcoms: a comparison. META 54 (3). 485-502.

Messerli, Thomas. 2017. Participation structure in fictional discourse in Miriam Locher \& Andreas Jucker (eds.) de Gruyter Handbooks of Pragmatics: Pragmatics of Fiction, 25-54. Berlin \& New York: Mouton de Grutyer.

Pavesi, Maria 2012. The enriching functions of address shifts in film translation in Aline Remael, Pilar Orero \& Mary Carroll (eds.), AVT and media accessibility at the crossroads. Media for All 3. Amsterdam/New York: Rodopi, 335-356.

Pavesi, Maria 2016. Formulaicity in and across film dialogue: clefts as translational routines. Across Languages and Cultures 17(1). 99-121.

Pavesi, Maria 2018. Reapprasing verbal language in audiovisual translation: from description to application. Journal of Audiovisual Translation 1(1). 101-121.

Pavesi, Maria, Formentelli, Maicol \& Ghia, Elisa (eds) 2014. The Languages of Dubbing. Mainstream Audiovisual Translation in Italy. Bern: Peter Lang

Pérez-González, Luis 2007. Appraising dubbed conversation: Systemic functional insights into the construal of naturalness in translated film dialogue. The Translator 13 (1). 1-38.

Pinto, Derrin 2010. Lost in subtitle translations: The case of advice in the English subtitles of Spanish films. Intercultural Pragmatics 7 (2). 257-277.

Ramos Pinto, Sara and Gambier, Yves 2016. Target Special Issue Audiovisual Translation Theoretical and Methodological Challenges 28 (2). 
Ranzato, Irene 2010. Localising Cockney: Translating dialect into Italia in Jorge Díaz Cintas, Anna Matamala \& Joselia Neves (eds) New Insights into Audiovisual Translation and Media Accessibility: Media for All , 109-122. Amsterdam: Rodopi.

Ranzato Irene \& Serenella Zanotti (eds) 2018. Linguistic and cultural representation in audiovisual translation. London: Routledge.

Remael Aline 2003. Mainstream narrative film dialogue and subtitling: A case study of Mike Leigh's Secret \& Lies (1996). The Translator 9(2). 225-247.

Romero Fresco, Pablo 2009. Naturalness in the Spanish dubbing language: a case of not-so-close Friends. Meta 54. 49-72.

Kecskes, Istvan. 2014. Intercultural pragmatics. Oxford: Oxford University Press. 